\title{
Interferon Measurement
}

National Cancer Institute

\section{Source}

National Cancer Institute. Interferon Measurement. NCI Thesaurus. Code C81868.

The determination of the amount of interferon present in a sample. 